\title{
Diurnal and intraseasonal variation of UTLS vertical wind disturbance in the equatorial region and its relation to tropospheric convective activities
}

\author{
Toshiaki Kozu ${ }^{1}$, Yasu-Masa Kodama ${ }^{2}$, Yoshiaki Shibagaki ${ }^{3}$, Toyoshi Shimomai ${ }^{1}$, \\ Masayuki Kawashima ${ }^{4}$, and Simon P. Alexander ${ }^{5}$ \\ ${ }^{1}$ Shimane University, Matsue, Shimane 690-8504, Japan \\ ${ }^{2}$ Hirosaki University, Hirosaki, Aomori 036-8561, Japan \\ ${ }^{3}$ Osaka Electro-Communication University, Neyagawa, Osaka 572-8530, Japan \\ ${ }^{4}$ ILTS, Hokkaido University, Sapporo, Hokkaido 060-0819, Japan \\ ${ }^{5}$ Australian Antarctic Division, Kingston, Tasmania 7050, Australia
}

(Received November 25, 2007; Revised September 9, 2008; Accepted September 15, 2008; Online published May 14, 2009)

\begin{abstract}
Vertical wind variations in the Upper Troposphere and Lower Stratosphere (UTLS) measured by the Equatorial Atmosphere Radar (EAR) at Kototabang, Sumatra, between 2003 and 2005 but mainly in 2004, have been statistically analyzed to study the characteristics of wind variances associated with convective activity, which is related to gravity wave generation and propagation. The analyses are intended to characterize relatively short period disturbances of less than 12 hours and an energy propagation direction of a relatively high elevation angle, and to relate vertical wind variations to convective activity close to the EAR. Correlation analyses between vertical wind variations and rainfall show that the wind variances have a clear diurnal variation indicating probable effects of tropospheric convection. They also show some intraseasonal variation. However, there are no significant correlations with the Out-going Long-wave Radiation (OLR) anomaly. The correlations between variances at UT and LS suggest that the UTLS coupling of vertical wind variation through upward propagation of gravity wave is similarly evident in the afternoon during both the active and the inactive phase of OLR that is a proxy of large-scale convective activity.
\end{abstract}

Key words: Vertical wind, gravity wave, equatorial region, tropospheric convection, rainfall.

\section{Introduction}

It is well known that tropospheric convection is the major source of gravity waves in the equatorial region. A wide spectrum of gravity waves is generated by convection (Fovell et al., 1992; Alexander et al., 1995), and interacts with the background atmosphere. High frequency gravity waves propagate with high elevation angles, and transport significant amounts of momentum flux (Alexander et al., 2000). They transport a large amount of momentum and kinetic energy to the upper atmosphere, and affect its global circulation. Alexander and Holton (1997) estimated that about $1 / 4$ of the zonal forcing required for the generation of the Quasi-Biennial Oscillation (QBO) in the stratosphere could be due to convectively-generated mesoscale gravity waves. Therefore temporal and spatial variations of such convectively-induced short-period gravity waves may have a significant effect on the characteristics of wave structures in the stratosphere.

The detection and characterization of short-period gravity waves are not easy. Radiosonde observations usually have sampling intervals of more than half a day. Satellite measurements allow for the global mapping of temperature in the stratosphere but have only sparse sampling and coarse horizontal resolution, limiting the use of satel-

Copyright (c) The Society of Geomagnetism and Earth, Planetary and Space Sciences (SGEPSS); The Seismological Society of Japan; The Volcanological Society of Japan; The Geodetic Society of Japan; The Japanese Society for Planetary Sciences; TERRAPUB. lite data for the survey of large scale gravity wave characteristics. Only VHF atmospheric radars can provide hightemporal and vertical resolution wind data in the upper troposphere to lower stratosphere (UTLS) region, where gravity waves are excited and propagate upward, although measurement locations are limited. One possible problem is that the refractive index fluctuations causing radar returns in this region are significantly less than in the mid- to lowertroposphere, so data gaps may exist. This is especially true for horizontal winds for which multiple oblique beams must be used to derive the wind speed. Vertical winds are easier to measure than horizontal winds since only a vertical beam is required, where radar echo intensity is usually stronger than in the case of oblique beams.

There has been a number of convection-induced gravity wave observations in the UTLS in the tropics where convection is expected to be a major source of gravity waves (e.g., Tsuda et al., 1994; Dutta et al., 1999; Alexander et al., 2000). Extensive radiosonde observations around Darwin Australia (DAWEX) provided a detailed model calculation of gravity wave characteristics due to convection (Alexander et al., 2004). Event analyses of convection-induced gravity waves were conducted using the Indian MST radar (Dhaka et al., 2003). However, most of the studies were limited to relatively short periods ranging from a few cases to a few months. Data from the Equatorial Atmosphere Radar (EAR) (Fukao et al., 2003), located just on the equator at a mountainous site in West Sumatra, Indonesia, have 
also been utilized in order to study gravity wave and vertical wind properties (Dhaka et al., 2005; Yamamoto et al., 2007) under the Coupling Processes in Equatorial Atmosphere (CPEA) project (Fukao, 2006). Alexander et al. (2006) made a detailed study of the vertical wind, temperature and humidity in the UTLS region using the EAR, EAR/RASS and X-band Doppler radar observations during the first CPEA campaign in April to May 2004. Recently Alexander et al. (2008) and Dutta et al. (2008) studied the long-term behavior of UTLS wind variances and momentum fluxes and correlations with Outgoing Long-wave Radiation (OLR) derived from thermal IR channel data of geostationary meteorological satellites, and with rainfall and storm height data from the Precipitation Radar (PR) onboard the Tropical Rainfall Measuring Mission (TRMM) satellite. Both papers discussed relatively long-term statistics such as monthly means. These studies demonstrated that the tropospheric convection generates short term disturbances in the UTLS region.

A caution should be made when using the vertical wind variation since it may not be a direct representation of tropospheric gravity waves because of the existence of various turbulent processes in convection. In heavy convection, we observe large variations in the troposphere, but only a part of such variation should become freely propagating gravity waves and causes the variation of vertical wind in the stratosphere. In a minority cases, however, the "direct" convective turbulences may reach the lower stratosphere of $17 \sim 19 \mathrm{~km}$ altitudes.

In this paper, we focus our attention on the climatological features of vertical wind variations having periods of $\leq 12$ hours as measured by the EAR between 2003 and 2005 but mainly in 2004, and study its diurnal and intraseasonal variations. These variations are also related to the OLR and to time-space-averaged rain rate derived from an X-band rain radar co-located with the EAR. In the following sections, we first describe the instruments and observation data used for this study. Section 3 describes the statistics of vertical wind variations, focusing on diurnal and intraseasonal variations. In Section 4, we make some discussion on the UTLS coupling based on the results in Section 3.

\section{Instruments and Data Used}

The location of the observation site is the EAR observatory, Kototabang $\left(0.20^{\circ} \mathrm{S}, 100.32^{\circ} \mathrm{E}, 865 \mathrm{~m} \mathrm{ASL}\right)$, west Sumatra, Indonesia. For the present analysis, we use the EAR, an X-band rain radar, an optical rain gauge (ORG), and the OLR from geostationary meteorological satellites. The EAR is a large aperture VHF radar that can measure the UTLS winds. However, because of insufficient transmitter power, there are significant data gaps especially at 14 to $16 \mathrm{~km}$, and above $20 \mathrm{~km}$ (Alexander et al., 2008). For a detailed explanation of the EAR, refer to Fukao et al. (2003). The X band rain radar, located near the EAR, is a conventional pulse radar that obtains the 2-D rain field within a radius of $64 \mathrm{~km}$. The configuration of instruments at Kototabang is shown in Fig. 1. The actual line-of-sight distance from the X-band rain radar to the center of the EAR antenna is about $100 \mathrm{~m}$.

The EAR vertical wind data are quality-checked with

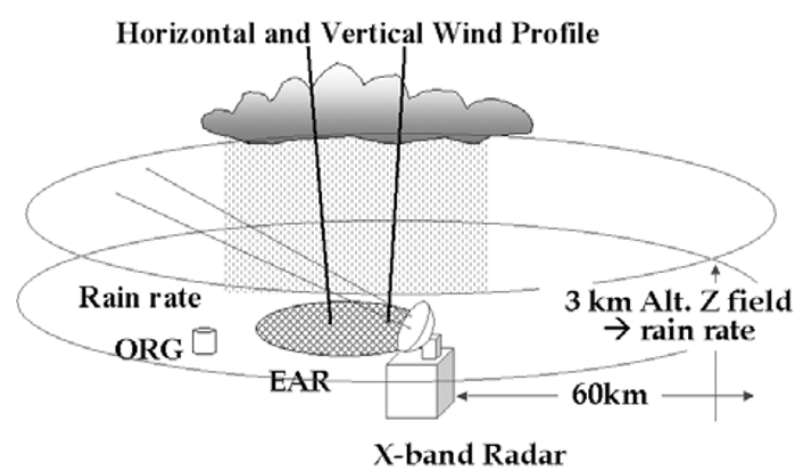

Fig. 1. Configuration of instruments at Kototabang.

a spectral fitting process and temporal-height filtering, and averaged over 10 minutes to reduce random noise (Hashiguchi, private communication, 2007). The preprocessed EAR data with 10-minute interval are first trendremoved with a quadratic fitting each day, then used to calculate the variance within half a day $(0 \sim 12$ LT and 12 24 LT) or 6-hour period (for an initial study of diurnal variation) for the height ranges of between $11 \mathrm{~km}$ and $13 \mathrm{~km}$, and between $17 \mathrm{~km}$ and $19 \mathrm{~km}$ to study the UTLS vertical wind variations. The EAR data sampling interval is $0.15 \mathrm{~km}$ starting at $2.065 \mathrm{~km}$. The $11 \sim 13 \mathrm{~km}$ and $17 \sim 19 \mathrm{~km}$ variances are calculated from the data at 3 altitudes nearest to the specified altitudes (i.e., 11.065, 11.965, and $13.015 \mathrm{~km} ; 17.065,17.965$, and $19.015 \mathrm{~km}$ ). The minimum acceptance rate of $50 \%$ is set in the calculation of the variance within each half-day period as was adopted in Alexander et al. (2008).

The OLR data of 2.5-deg grid resolution are regularly provided by the National Oceanic and Atmospheric Administration (NOAA). We are using the OLR anomaly data provided by Dr. M. Wheeler, BMRC, Australia (private communication, 2007). For a detailed explanation of the anomaly calculation, see Wheeler and Kiladis (1999). We use only the data averaged over $97.5^{\circ} \mathrm{E}$ to $102.5^{\circ} \mathrm{E}$ in longitude and $2.5^{\circ} \mathrm{S}$ to $2.5^{\circ} \mathrm{N}$ in latitude as a proxy for the large scale tropospheric convective environment.

The X-band radar scans the $64-\mathrm{km}$ radius about every 10 minutes. We have made half-day averages of the 10 min area-averaged rain rate at $3-\mathrm{km}$ altitude above ground level to study the diurnal variation of UTLS coupling of wind disturbances related to local rainfall activity. For the conversion of radar reflectivity factor $(Z)$ to rain rate $(R)$, we assume the Marshall-Palmer $Z-R$ relation, $Z=200 R^{1.6}$ (Doviak and Zrnic, 1993). Since gravity waves do not propagate only in the vertical, the ORG data located just at the EAR site may not be a good representation for comparison with the EAR derived UTLS wind. On the other hand, $\mathrm{X}$-band radar-based area-averaged data cover the elevation angles within about several degrees (assuming a gravity wave source $60-\mathrm{km}$ apart with the altitude of $3 \sim 7 \mathrm{~km}$, and $11 \sim 13-\mathrm{km}$ altitudes to consider wind variation) to zenith, so a wide spectrum of short period gravity waves are expected to be related to the EAR vertical wind data. A comparison between ORG-measured daily rainfall and radarderived daily area rainfall has been found to be consistent 


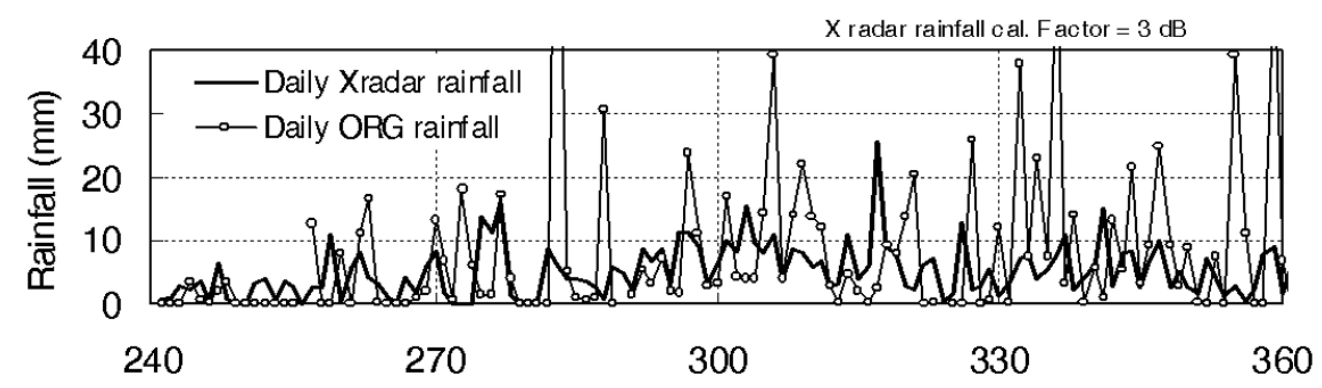

Julian day, 2004

Fig. 2. Comparison of ORG-measured daily rainfall and X-band-radar-derived area-averaged daily rainfall for about September to December, 2004.

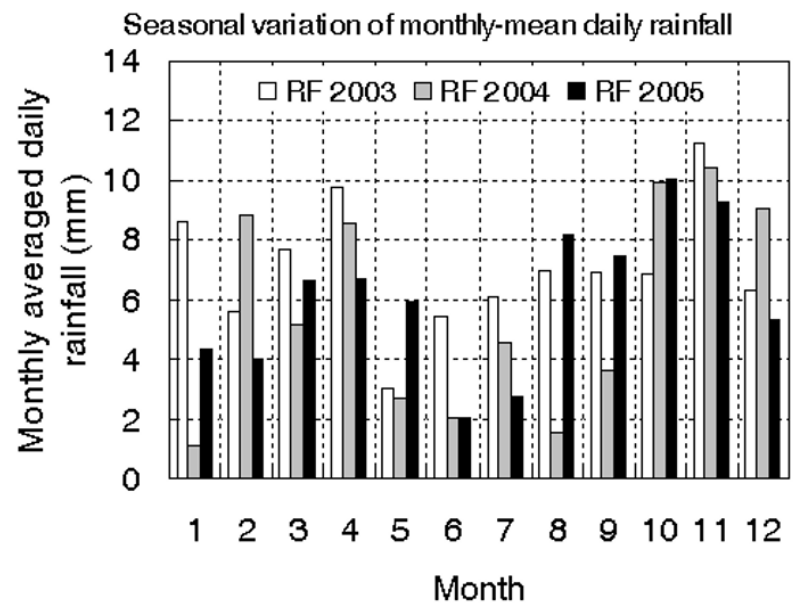

Fig. 3. Monthly averaged daily rainfall measured by ORG at Kototabang for 2003, 2004, and 2005 .

with one another except for a "pulse-like" feature in the ORG rainfall time series data, as shown in Fig. 2.

Rainfall occurs throughout the year in Kototabang; however, there are two mild rainy seasons, one in November to December, and the other in March to April, as shown in Fig. 3. In addition to the relatively mild seasonal variation, there are significant intraseasonal variations for periods of about 10 days to several tens of days due to the passage of super cloud clusters (SCCs) and the MaddenJulian Oscillation (MJO) (Madden and Julian, 1994). Usually such intraseasonal variations are documented by a wave number-frequency spectrum analysis of OLR (e.g., Wheeler and Kiladis, 1999). The time-longitude diagram of the OLR (refer to BMRC, 2008, for an example) clearly shows the propagation of the MJO from the Indian Ocean to the Pacific. The OLR signature somewhat changes around the longitude of $100^{\circ} \mathrm{E}$ where a convective field hits the high mountain range of West Sumatra where Kototabang is located. Therefore, interactions between the large-scale convective activity such as the MJO and local circulation may produce complicated convective characteristics in the Kototabang area. Figure 4 shows the periodogram of the OLR anomaly around Kototabang from 1999 to 2006. The peak around 30 to 40 days corresponds to the MJO. Considering that the number of incoherent average is 36 , the normalized standard deviation of the spectrum is about $17 \%$. There-

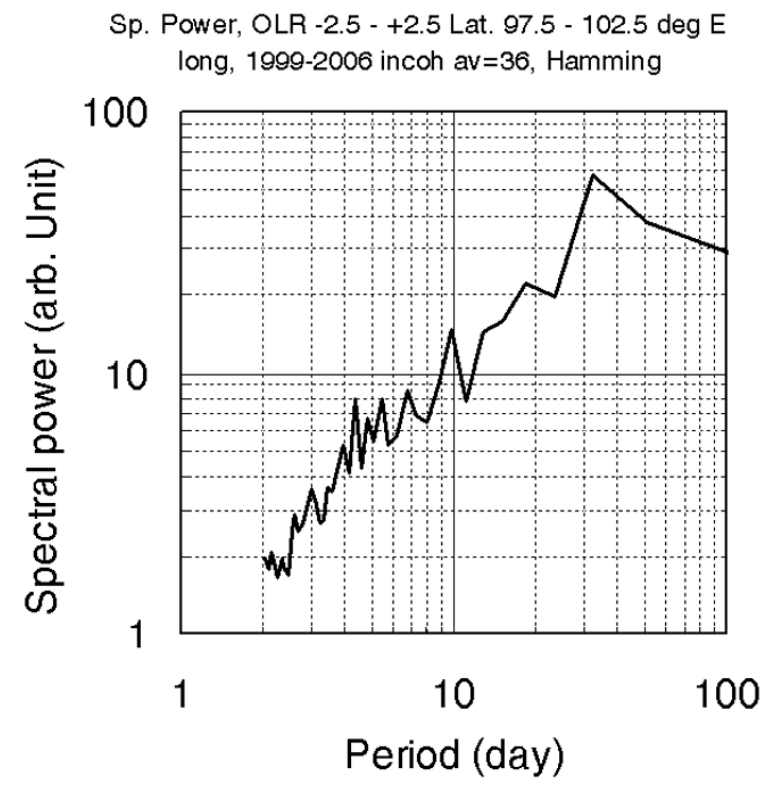

Fig. 4. Periodogram of OLR anomaly between 1999 and 2006.

fore, the peak around 10 days, which may correspond to SCC, may also be statistically significant. To analyze the intraseasonal variation of the UTLS vertical wind variation, therefore, we use the 9-day low-pass-filtered OLR anomaly throughout the following discussion.

As described by Kozu et al. (2005), Kawashima et al. (2006), Kodama et al. (2006), and Morita et al. (2006), localized and deep convection is active during the inactive phase of MJO, so that significant rainfall may also be observed even in the inactive phase and rainfall characteristics appear to be different in the MJO active and inactive phases. Variations in rainfall characteristics have also been found along with the phase of SCC (Shibagaki et al., 2006). Therefore our interest is how the vertical wind disturbances depend on the large-scale atmospheric environment represented by the OLR anomaly showing an intraseasonal variation.

\section{Statistical Properties of UTLS Vertical Wind Variance $\left(\overline{w^{\prime 2}}\right)$ \\ 3.1 Outline}

The wind data from the EAR suffer from data gaps, especially between 14 and $16 \mathrm{~km}$ (Alexander et al., 2008). 
(a) $\rightarrow$ VAR. $11-13 \mathrm{~km}, \mathrm{AM} \quad \longrightarrow$ - VAR. $11-13 \mathrm{~km}, \mathrm{PM} \quad$ OLR anom aly Vertical wind variance, from EAR at $11-13 \mathrm{~km}$ in AM and PM, 2004

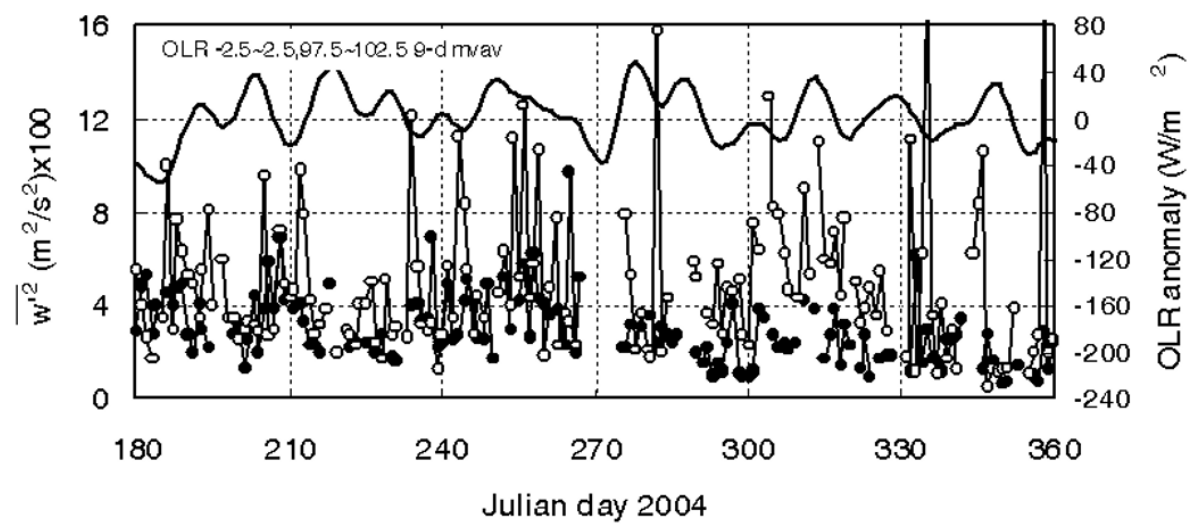

(b) $\rightarrow$ VAR. $17-19 \mathrm{~km}$, AM $\multimap$ VAR. $17-19 \mathrm{~km}, \mathrm{PM} \quad \longrightarrow$ OLR anomaly
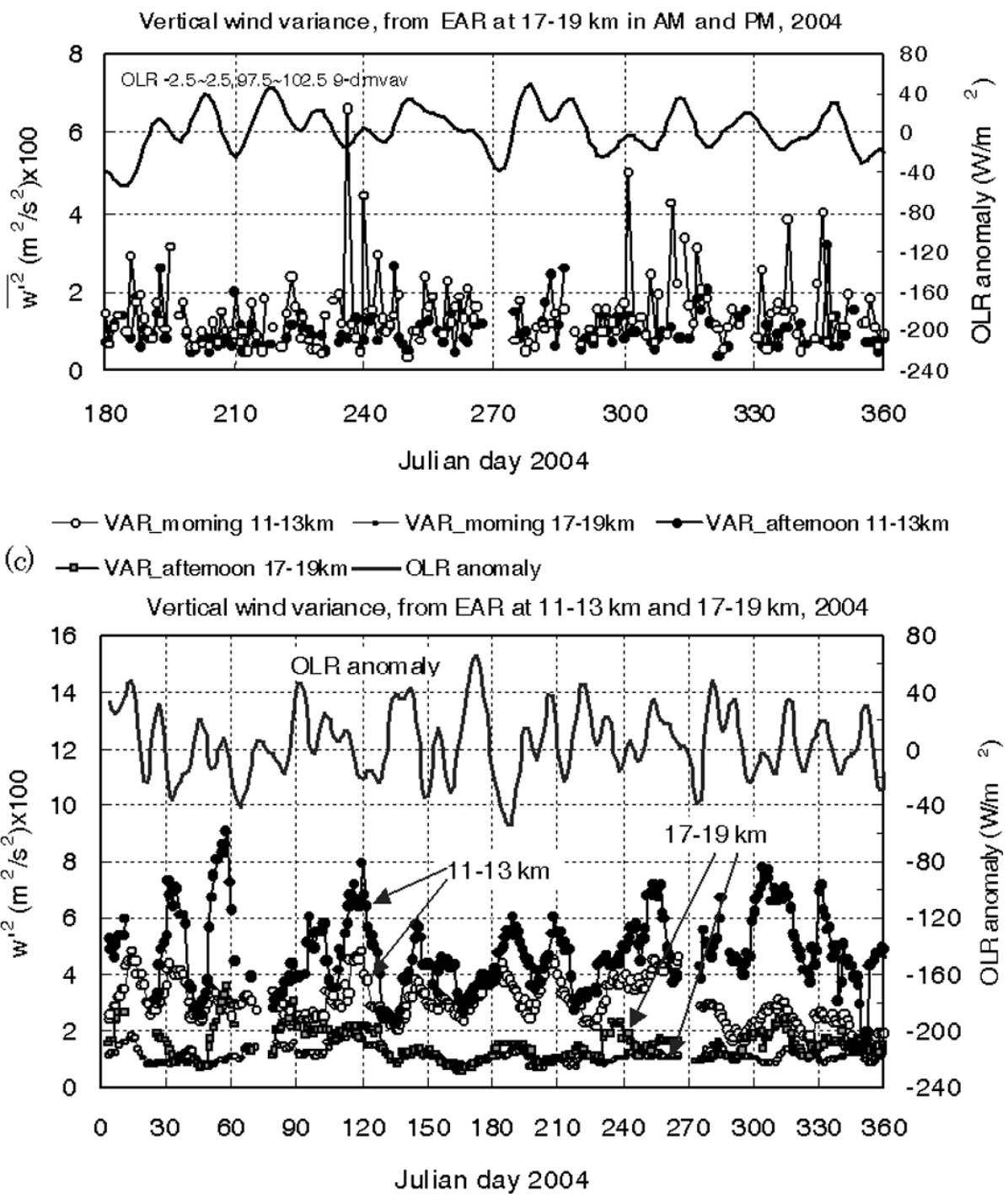

Fig. 5. Variations of $\overline{w^{\prime 2}} \mathrm{~s}$ in morning $(0 \sim 12 \mathrm{LT})$ and afternoon (12 24 LT) for altitudes at $11 \sim 13 \mathrm{~km}$ and $17 \sim 19 \mathrm{~km}$, in comparison with OLR anomaly in 2004. (a) and (b) show the latter half of 2004 for $11 \sim 13 \mathrm{~km}$ and $17 \sim 19 \mathrm{~km}$, respectively, and (c) shows 9-day moving averaged $\overline{w^{\prime 2}}$ data to reduce short-term fluctuation for the entire 2004. 
Therefore we focus our attention on two height ranges: one is the upper troposphere between 11 and $13 \mathrm{~km}$, and the other in the lower stratosphere between 17 and $19 \mathrm{~km}$. It is expected that the variance at the $11 \sim 13 \mathrm{~km}$ range is directly affected by convective forcing. On the other hand, at $17 \sim 19 \mathrm{~km}$ it should be more greatly affected by gravity waves mainly generated by the tropospheric convection, although there may still be "direct" turbulence induced by very deep convective activities.

Figure 5 illustrates the variation of $11 \sim 13-\mathrm{km} \overline{w^{\prime 2}}$ and $17 \sim 19-\mathrm{km} \overline{w^{\prime 2}}$ in the morning (0 to $12 \mathrm{LT}$ ) and afternoon (12 to 24 LT) along with the OLR anomaly in 2004 ((a) and (b) show only the latter half of 2004 for clarity). From the upper two figures, we find that $\overline{w^{\prime 2}}$ varies significantly day-by-day. In these figures we can also see some intraseasonal variation of $\overline{w^{\prime 2}}$ with the period of 10 to 30 days. To see the intraseasonal variation more clearly, we made a 9-day moving average of $\overline{w^{\prime 2}}$ and removed the shortterm variation, which is shown in Fig. 5(c) for 1 year. We can recognize that a significant intraseasonal variation in $\overline{w^{\prime 2}}$ exists. In addition, there is a clear difference between $11 \sim 13 \mathrm{~km} \overline{w^{\prime 2}}$ and $17 \sim 19-\mathrm{km} \overline{w^{\prime 2}}$ in which the former is generally much higher, and between morning $\overline{w^{\prime 2}}$ and afternoon $\overline{w^{\prime 2}}$ in which the latter is generally higher. This type of diurnal variation was also shown in Alexander et al. (2006) for which they used data between April and May 2004 only. In our case, we find similar characteristics using a much longer database.

The correspondence between OLR anomaly and $\overline{w^{\prime 2}}$ is not clear; in some high OLR cases, i.e., convectively inactive period, $\overline{w^{\prime 2}}$ shows high values (e.g., around days 255 and 330,2004$)$. This suggests that the vertical wind variation is affected not only by large-scale convective activity but other causes such as the local convection having shorter periods than the intraseasonal variation of the OLR. Spectral analysis of $\overline{w^{\prime 2}}$ is difficult because of the frequent gaps in the EAR vertical wind data. Therefore, we discuss the intraseasonal variation of $\overline{w^{\prime 2}}$ only qualitatively at present. More discussion will be made in Section 3.3 by classifying the active and inactive phases of large-scale convective activity which is represented by the OLR anomaly.

\subsection{Diurnal variation}

Considering the result of the analysis of April to May 2004 EAR data (Alexander et al., 2006), there should be clear diurnal variations in $\overline{w^{\prime 2}}$ for other seasons as well. First, we try to find out what is the dominant period contributing to the vertical wind perturbation $\left(w^{\prime}\right)$ within a day. Unfortunately, it is difficult to make a spectrum analysis because there are many gaps in the time series of EAR $w^{\prime}$ data. Nevertheless, we have tried to find relatively continuous half days (AM and PM) within which the length of each data gap is equal to or less than 3 (30 minutes). After linear interpolations to fill these gaps, we made an FFT of this data series and made an incoherent average of the power spectra for the one year period of 2004. The result is shown in Fig. 6. The total number of the average is about 160 to 170 for the 4 spectra shown in the figure, so that the normalized standard deviation of the spectra is about $8 \%$. As shown in this figure, the spectral intensities of $w^{\prime}$ having periods of
Averaged half day w' spectrum, 12 and $18 \mathrm{~km}, 2004$

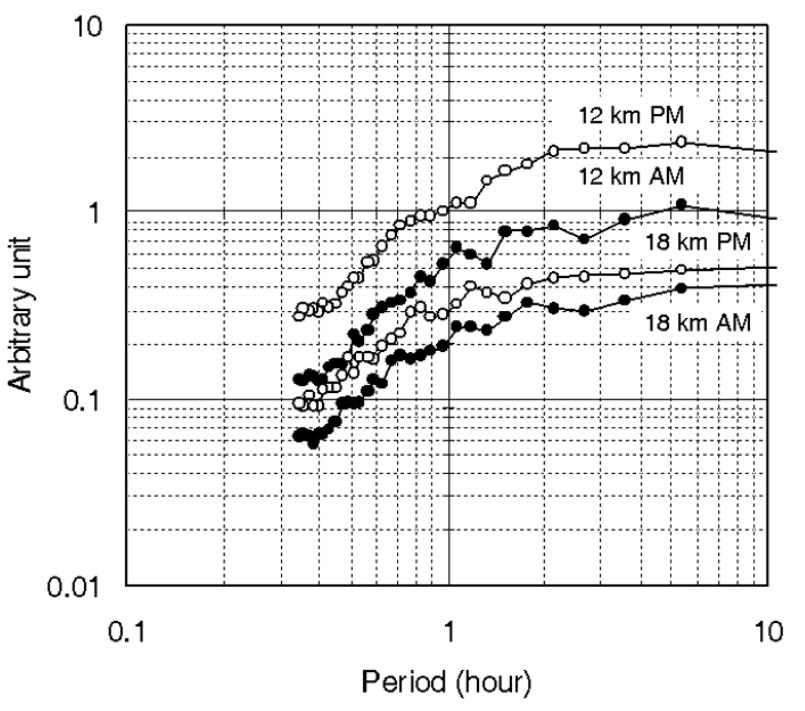

Fig. 6. Periodograms of $12-\mathrm{km}$ and $18-\mathrm{km} w^{\prime}$ s within half day (AM and PM) averaged over selected "good" days in 2004.

2 hours or longer are almost flat, independent of altitude. This indicates a wide range of turbulence and gravity waves contributing to vertical wind variation.

We have also calculated the variance of $w^{\prime}$ during 6 hours with 2-hour shift and averaged over one month to examine the outline of diurnal variation of $\overline{w^{\prime 2}}$ as shown in Fig. 7. Although the period of $w^{\prime}$ concerned is up to 6 hours in this analysis, it is useful to qualitatively understand the outline of the diurnal variation of $\overline{w^{\prime 2}}$. The local time in the abscissa represents the center of the 6-hour period to obtain $\overline{w^{\prime 2}}$. It appears that before and after $12 \mathrm{LT}, \overline{w^{\prime 2}}$ is much different. Therefore, we present the results of the characteristics of $\overline{w^{\prime 2}}$ for AM $(0 \sim 12$ LT) and PM (12 24 LT).

Following are comparisons of morning and afternoon vertical wind variances $\left(\overline{w^{\prime 2}} \mathrm{AM}\right.$ and $\left.\overline{w^{\prime 2}} \mathrm{PM}\right)$ from several viewpoints. Figure 8 shows the cumulative distribution of $\overline{w^{\prime 2}} \mathrm{AM}$ and $\overline{w^{\prime 2}} \mathrm{PM}$ for 2003 to 2005 . The difference in magnitude of $\overline{w^{\prime 2}}$ s between the morning and the afternoon is clearly seen from this figure. There are about 3 to 5 times differences in $12-\mathrm{km} \overline{w^{\prime 2}}$ and $18-\mathrm{km} \overline{w^{\prime 2}}$, depending on the local time, morning or afternoon. It appears that the ratio of $18-\mathrm{km} \overline{w^{\prime 2}}$ to $12-\mathrm{km} \overline{w^{\prime 2}}$ is somewhat larger in the morning, suggesting that the variation directly caused by the afternoon convection affects the $12-\mathrm{km} \overline{w^{\prime 2}}$ to a greater degree than the $18-\mathrm{km} \overline{w^{\prime 2}}$. The medians (50\% value) of $12-\mathrm{km}$ $\overline{w^{\prime 2}} \mathrm{AM}$ and $12-\mathrm{km} \overline{w^{\prime 2}}$ PM are $2.4 \times 10^{-2}$ and $3.6 \times 10^{-2}$, respectively, while those of $18-\mathrm{km} \overline{w^{\prime 2}} \mathrm{AM}$ and $18-\mathrm{km} \overline{w^{\prime 2}} \mathrm{PM}$ are $0.9 \times 10^{-2}$ and $1.2 \times 10^{-2}$, respectively.

To examine the relation between rainfall and vertical wind variations, a correlation analysis is performed between the half-day averaged area rain rate derived from the X-band radar and $\overline{w^{\prime 2}}$, the result of which is shown in Fig. 9. The correlation is higher in the afternoon than in the morning for both $11 \sim 13 \mathrm{~km} \overline{w^{\prime 2}}$ and $17 \sim 19 \mathrm{~km} \overline{w^{\prime 2}}$. However, the correlation coefficients at the $17 \sim 19 \mathrm{~km}$ range are low, and the difference in values between AM and PM is small. We 


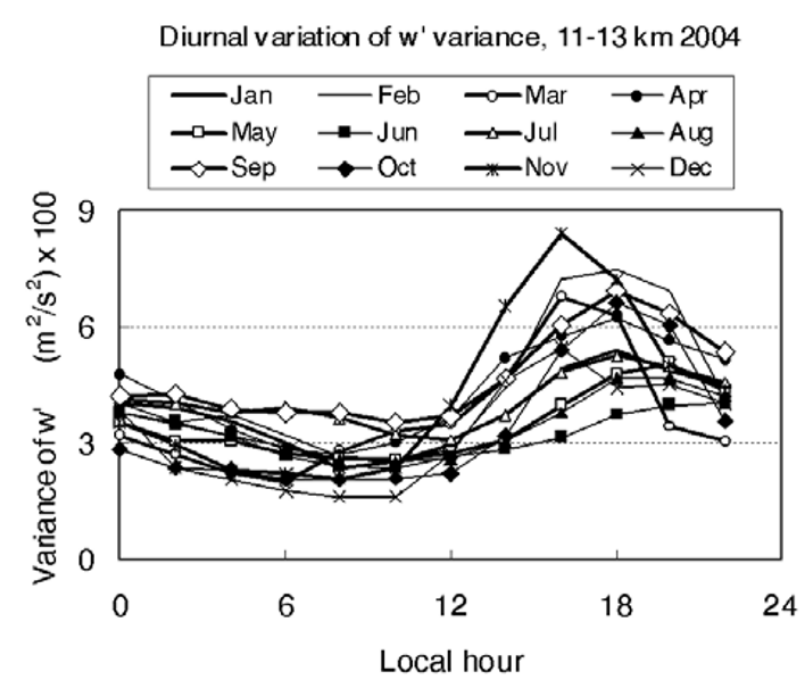

Diurnal variation of $w^{\prime}$ variance, $17-19 \mathrm{~km} 2004$

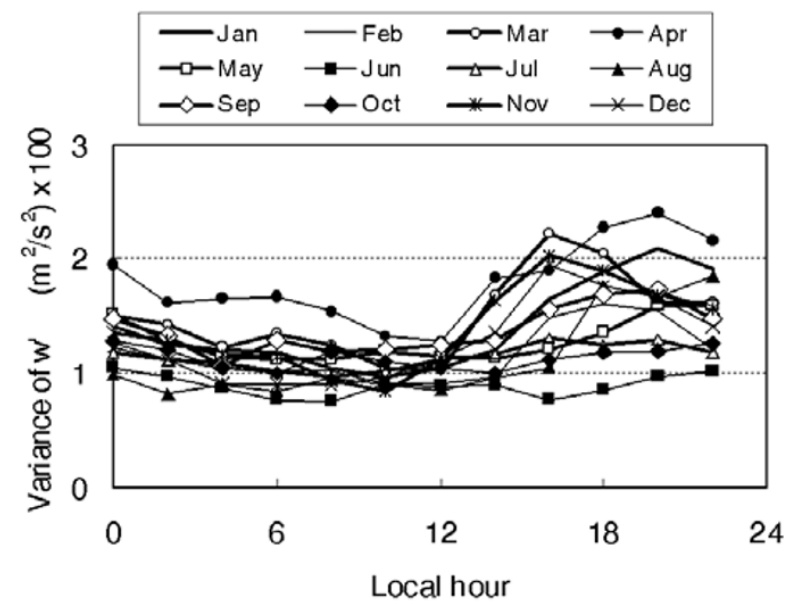

Fig. 7. One-month averaged diurnal variation of $\overline{w^{\prime 2}}$ within 6 hours. Center local time of the 6 hours is shifted by 2-hour step and the diurnal variation is obtained. Upper panel: $11 \sim 13 \mathrm{~km}$. Lower panel: $17 \sim 19 \mathrm{~km}$.

suppose that this small difference is due to the fact that at the $17 \sim 19 \mathrm{~km}$ range, wind disturbances are much more affected by gravity wave sources different from the local convective activity in the troposphere. Nevertheless, the interval estimates of the correlation coefficients shown in Fig. 9 indicate that even at the $17 \sim 19 \mathrm{~km}$ range, the correlation coefficient is clearly positive. This result suggests that the rainfall is a potential cause of UTLS vertical wind variation, since a clear diurnal variation of rainfall at Kototabang has already been presented (figure 4 in Kozu et al., 2006) and is evident from Fig. 9. Note, however, that the vertical wind fluctuations are not only caused by the turbulence due to convective rain around the EAR. The $12-\mathrm{km} \overline{w^{\prime 2}}$ would also contain a large degree of wind turbulence inside and just above the convection, not gravity waves. This may be one of the causes of the large variability observed in the $12-\mathrm{km} \overline{w^{\prime 2}} \mathrm{PM}$.

\subsection{Intraseasonal variation}

As mentioned above, extensive studies on the MJO responses of raindrop size distribution (Kozu et al., 2005), vertical rain structure (Kawashima et al., 2006), lightning,

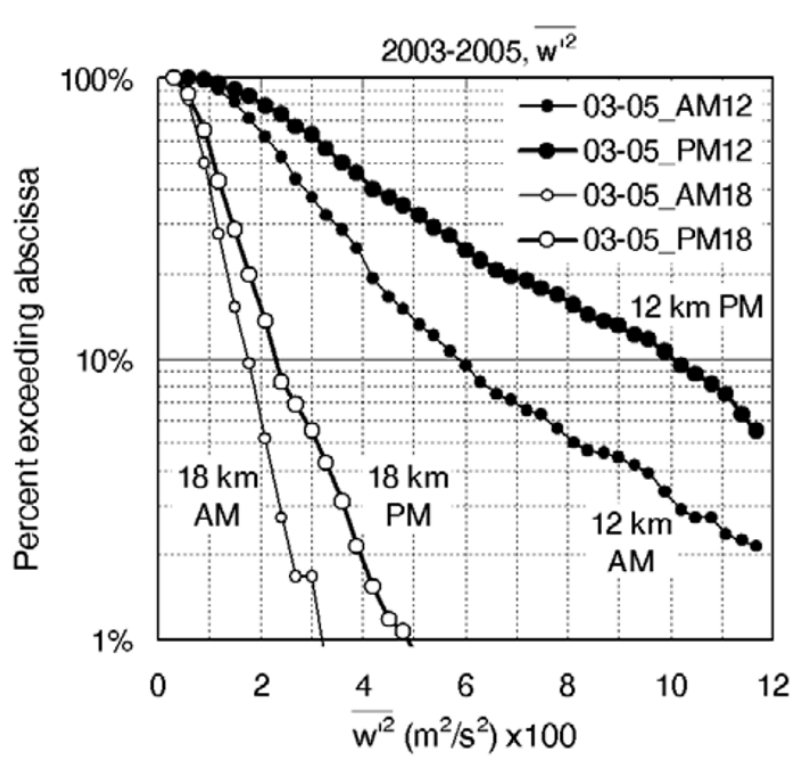

Fig. 8. Cumulative distributions of $\overline{w^{\prime 2}}$ from 2003 to 2005 .

and heating profile (Kodama et al., 2006) were conducted during the CPEA campaign (April to May 2004). These results indicate that although the total rainfall amount in the active phase is generally larger than in the inactive phase, individual convection may be more intense in the inactive phase. The dependence of $\overline{w^{\prime 2}}$ on the OLR anomaly in 2004 is shown in Fig. 10. Generally speaking, the correlation is so low that the OLR cannot be used as a measure of characterizing $\overline{w^{\prime 2}}$. However, this does not necessarily mean that there is no "OLR" phase dependence in $\overline{w^{\prime 2}}$ characteristics. Therefore, we make an analysis of vertical wind variation by classifying the OLR into active and inactive phases. The active and inactive phases are defined as periods when the OLR is lower than $-10 \mathrm{~W} / \mathrm{m}^{2}$ and higher than $+10 \mathrm{~W} / \mathrm{m}^{2}$, respectively. This threshold was determined by referring to the BMRC equatorial wave analysis (BMRC, 2008). Note that "OLR active and inactive phases" defined here are similar to "MJO active and inactive phases", except that the former has a shorter period (down to about 9 days) than the MJO period.

Figure 11 shows the correlations between $12-\mathrm{km} \overline{w^{\prime 2}}$ and $18-\mathrm{km} \overline{w^{\prime 2}}$ for the OLR active and inactive phases between April 2004 and March 2005. In the morning (AM; left panels), the magnitudes of $12-\mathrm{km}$ and $18-\mathrm{km} \overline{w^{\prime 2}} \mathrm{~s}$ are not significantly different between the active and inactive phases and show little correlation in both phases. In the afternoon (PM; right panels), the magnitudes of $18-\mathrm{km} \overline{w^{\prime 2}} \mathrm{~s}$ in the OLR active and inactive phases are similar to one another, in spite of the slightly greater $12-\mathrm{km} \overline{w^{\prime 2}}$ in the active phase. The correlation coefficient between $12-\mathrm{km} \overline{w^{\prime 2}}$ and $18-\mathrm{km} \overline{w^{\prime 2}}$ is also slightly higher in the OLR inactive phase than in the active phase.

The relation between rainfall and $\overline{w^{\prime 2}}$ is also examined, which is shown in Fig. 12 as scattergrams between the halfday averaged area rain rate (derived from the X-band rain radar) and $\overline{w^{\prime 2}}$. Statistical t-tests are applied for individual correlation coefficients, which indicates that the "no cor- 

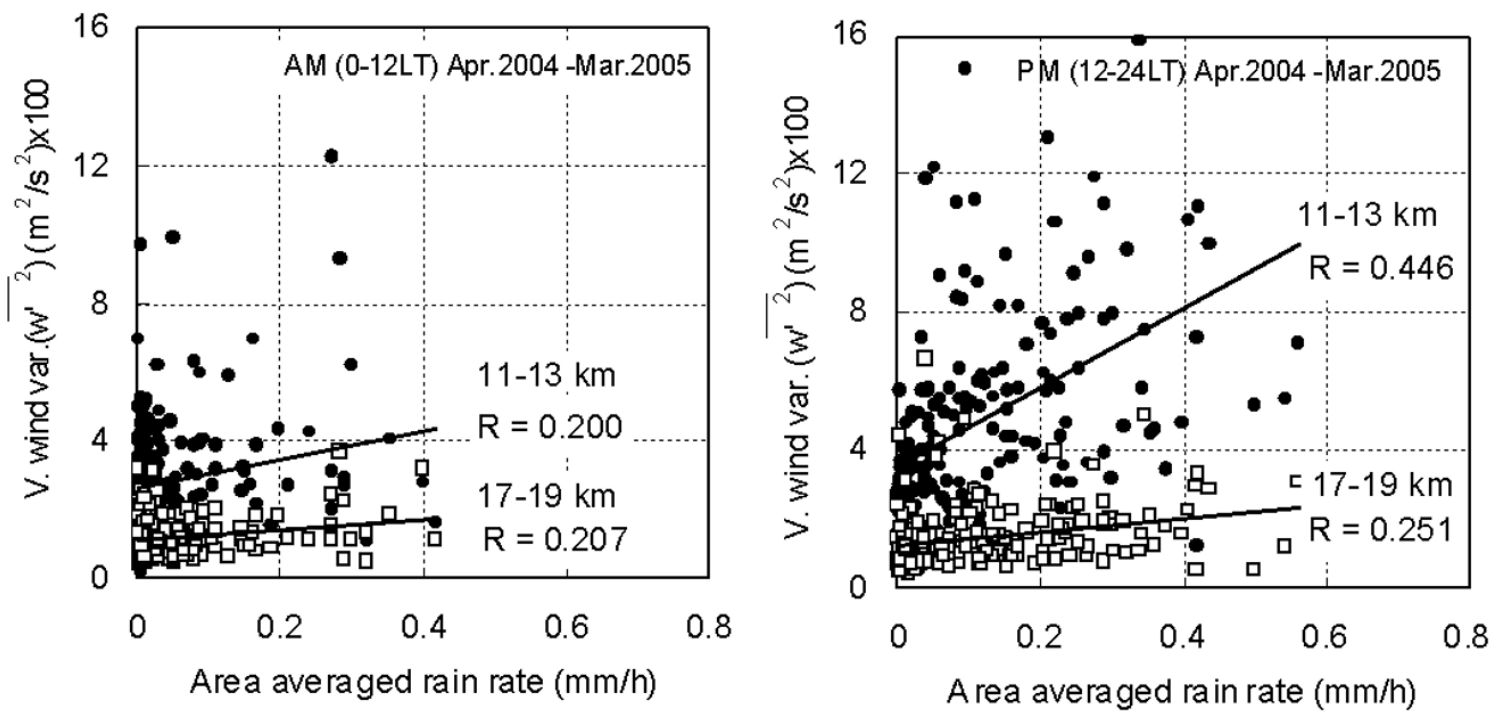

Fig. 9. Correlations between area-time-averaged rain rate and $\overline{w^{\prime 2}}$ in the morning (AM; left) and in the afternoon (PM; right) for $11 \sim 13 \mathrm{~km}$ and 17 19 km between April 2004 and March 2005.

OLR vs AM var., 2004

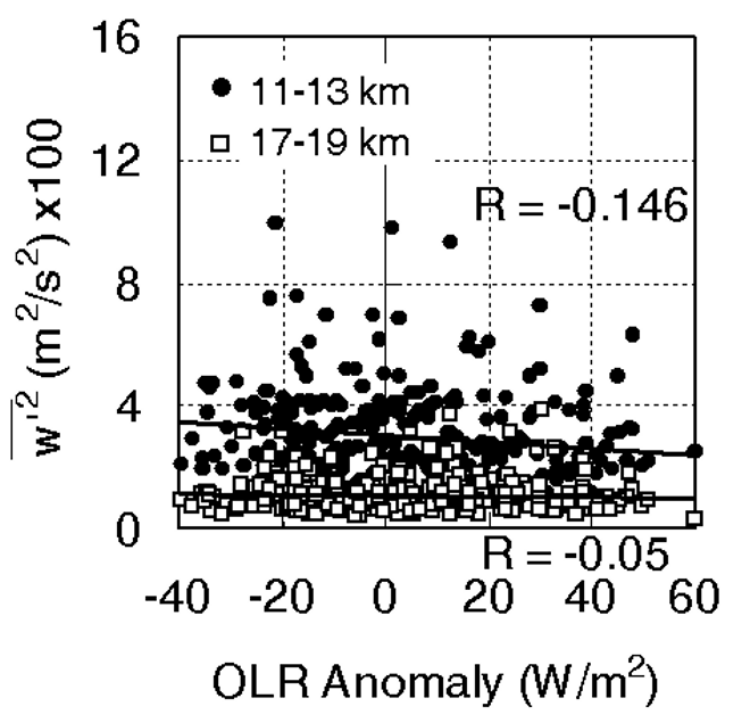

OLR vs PM var., 2004

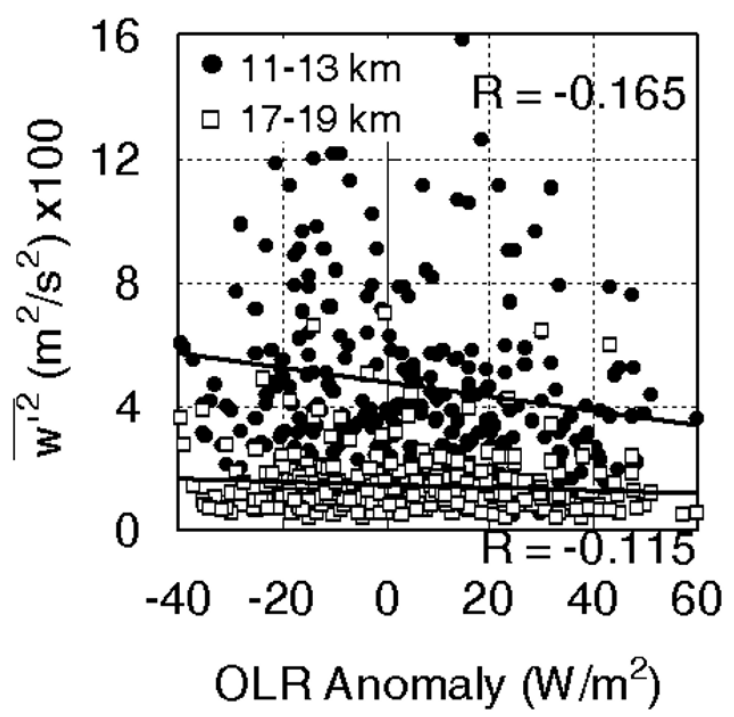

Fig. 10. Correlations between OLR anomaly and $\overline{w^{\prime 2}}$ in the morning (AM; left) and in the afternoon (PM; right) in 2004.

relation hypothesis" is not rejected for those in the morning (AM) of the active phase and for that in the afternoon (PM) of the active phase at 17 19 km. On the other hand, in the inactive phase, correlations are statistically significant. Slightly higher correlation coefficients in the OLR inactive phase than in the active phase suggest that vertical wind disturbances due to localized rainfall activity propagate slightly more evidently from the UT to the LS region of $17 \sim 19 \mathrm{~km}$ in the OLR inactive phase. There is also a possibility that deep convection reaching the lower stratosphere causes large wind disturbances both at the 11 13-km and 17 19-km altitudes especially in the inactive phase during which the convection tends to be deeper (Kawashima et al., 2006).

However, the difference between the active and inactive phases in the correlations shown in Figs. 11 and 12 are relatively small considering the large scatters seen in these figures. Therefore, we can conclude that the disturbances around $11 \sim 13 \mathrm{~km}$ affect those around 17 19 km similarly in the inactive phase and the active phase, even if there is a significant difference in rainfall characteristics between the active and inactive phases as mentioned above.

\section{Discussion}

From the results shown in Section 3, the following becomes evident: (1) clear diurnal variation in $\overline{w^{\prime 2}}$, especially at $11 \sim 13 \mathrm{~km}$, (2) some intraseasonal variation in $\overline{w^{\prime 2}}$ but not necessarily correlated with OLR anomaly, (3) positive correlation between rainfall and $\overline{w^{\prime 2}}$ in the afternoon especially at 11 13 km (see Fig. 9), and (4) slightly higher correlations between the $12-\mathrm{km} \overline{w^{\prime 2}}$ and $18-\mathrm{km} \overline{w^{\prime 2}}$ and between 

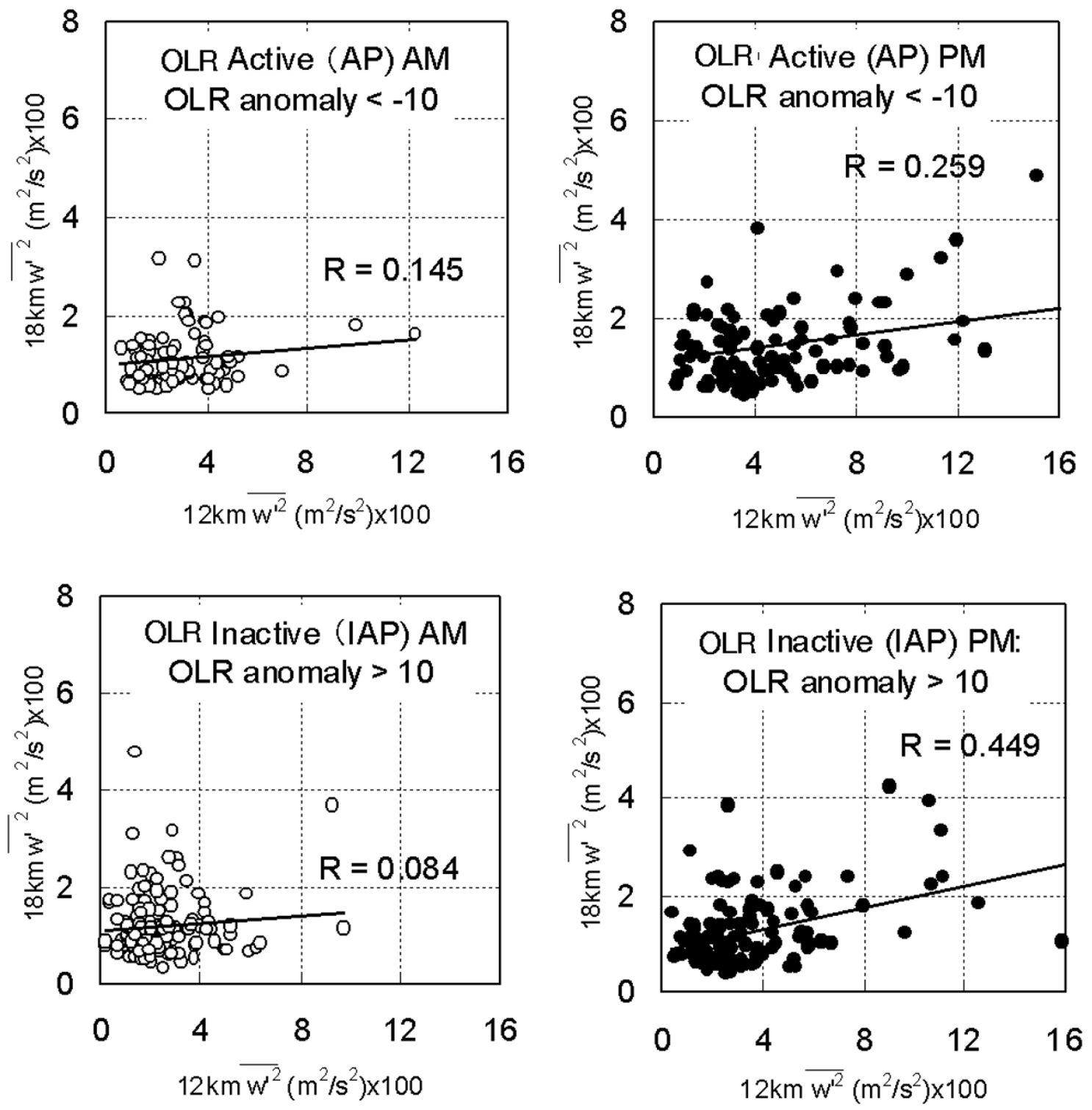

Fig. 11. Correlations between 12-km $\overline{w^{\prime 2}}$ and 18-km $\overline{w^{\prime 2}}$ for OLR active (upper panels) and inactive (lower panels) phases, in the morning (AM; left) and in the afternoon (PM; right).

rainfall and $\overline{w^{\prime 2}}$ in the OLR inactive phase than in the active phase, especially in the afternoon.

The findings (1) and (3) are probably related to the clear diurnal variation of rainfall activity in Kototabang, in which afternoon convection is evident. However, it should be noted that the diurnal variation depends on the location around Kototabang; near the coast line, rainfall peaks around midnight (Mori et al., 2004). Therefore, the diurnal variation may also depend on the location.

The finding (4) is anticipated from the results of CPEA campaign results discussed above, since we find localized, deep convection in the MJO inactive phase. The result is the existence of significant vertical wind variations in the inactive phase as well as in the active phase. Slightly lower correlations between rainfall and $\overline{w^{\prime 2}}$, and between $12-\mathrm{km}$ and $18-\mathrm{km} \overline{w^{\prime 2}} \mathrm{~s}$ in the OLR active phase may be related to the fact that widely spread organized rainfall systems outside the $\mathrm{X}$-band radar coverage cause gravity waves in the active phase. This effect would be small in the inac- tive phase. Although this type of "OLR-phase insensitivity" of the vertical wind variation, i.e., that $w^{\prime 2}$ s are similar both in the OLR active and inactive phases, is found at Kototabang, there may be different intraseasonal variations over the ocean because Kodama et al. (2006) found significant differences in atmospheric heating profile between the MJO active and inactive phases. On flat land, where orographic effects are weak, local convections in the OLR inactive phase may be insignificant, and the intraseasonal variation of vertical wind variation may also differ from those at Kototabang. Therefore, it is anticipated that in the Maritime continent, the characteristics of UTLS disturbances due to convection depend on location (land and ocean), and may exhibit different diurnal and intraseasonal variations.

\section{Summary}

We have performed a statistical analysis of vertical wind variations in the UTLS region measured by the EAR at Kototabang, Sumatra, between 2003 and 2005 but mainly in 

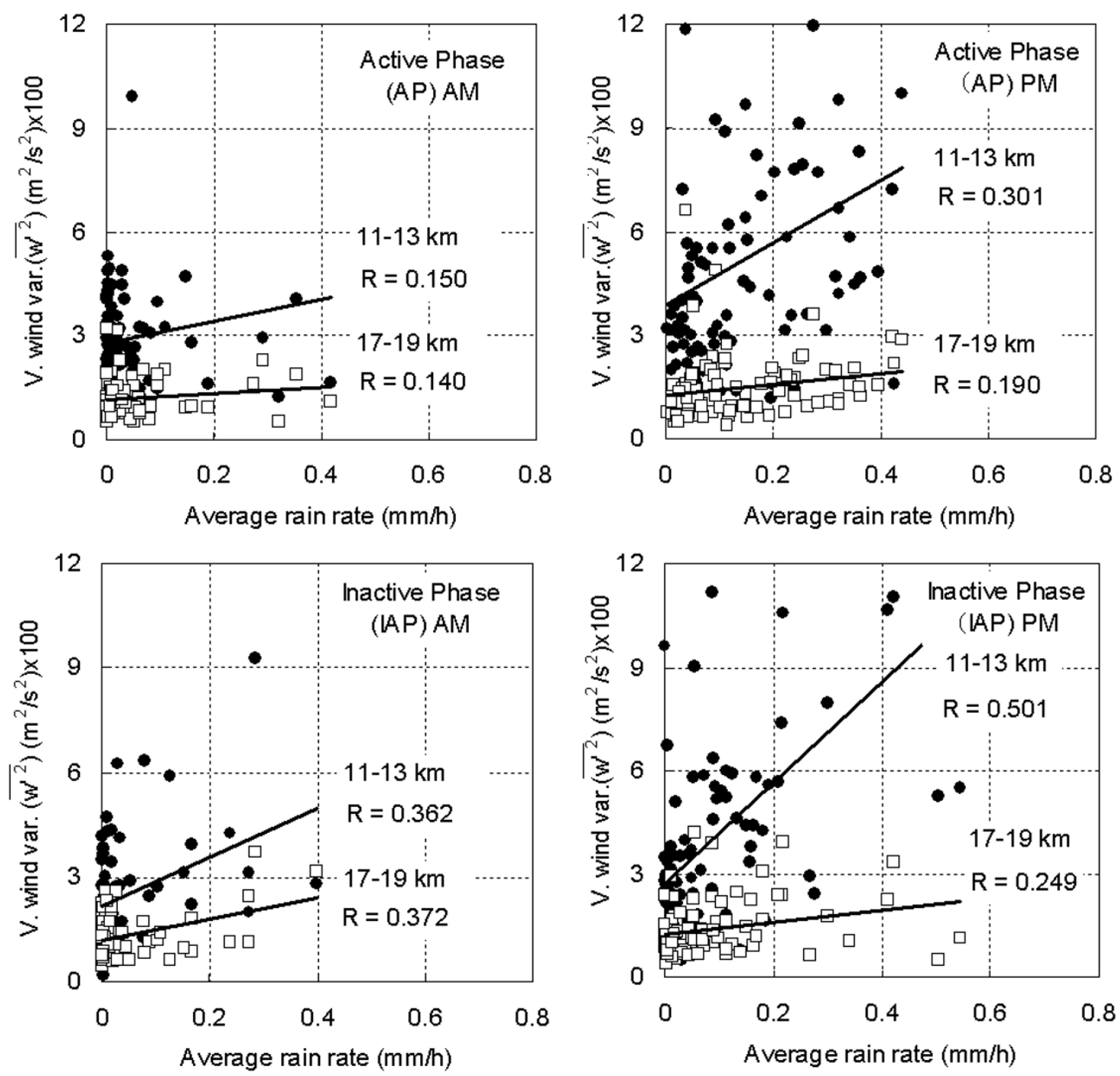

Fig. 12. Correlations between X-band radar derived average rain rate and $11 \sim 13 \mathrm{~km}$ and $17 \sim 19 \mathrm{~km} \overline{w^{\prime 2}}$ s for OLR active (upper panels) and inactive (lower panels) phases, in the morning (AM; left) and in the afternoon (PM; right) between April 2004 and March 2005.

2004, related to X-band radar derived rain rate and OLR anomaly, to study the gravity wave generation and propagation due to convective activity. The analyses were focused on short period variations having periods shorter than 12 hours and elevation angles of energy propagation of several degrees to near zenith (see the explanation in Section 2) that are expected to be generated from convective activities close to the EAR.

It was found that 12-hour- and area-averaged rain rate is positively correlated with vertical wind variance $\left(\overline{w^{\prime 2}}\right)$ in case it is in the afternoon (12-24 LT). Especially in the $11 \sim 13 \mathrm{~km}$ range, a clear difference is observed between the magnitude of $\overline{w^{\prime 2}} \mathrm{~s}$ in the morning $(0 \sim 12 \mathrm{LT})$ and in the afternoon. This is consistent with the significant diurnal variation of rainfall activity at Kototabang (Kozu et al., 2006), and indicates that the generation of convective gravity waves should have a clear diurnal variation as far as the Kototabang area is considered. Cumulative distributions of $\overline{w^{\prime 2}}$ indicates that the median of $\overline{w^{\prime 2}}$ in the afternoon is about 3 times greater than in the morning.

Some intraseasonal variation was also found in $\overline{w^{\prime 2}}$.
However, correlations between OLR anomaly and $\overline{w^{\prime 2}}$ are not significant. This suggests that local convective activities in the OLR inactive phase around Kototabang are sometimes more intense than those in the OLR active phase. This may also contribute to the wind variations and gravity wave generation in the inactive phase as well as in the active phase. Relating to the poor correlation between OLR anomaly and $\overline{w^{\prime 2}}$, analyses using TBB having higher spatial and temporal resolutions instead of OLR may be worth considering as a next step study. Correlations between $\overline{w^{\prime 2}}$ and the area-time averaged rain rate, and between $\overline{w^{\prime 2}} \mathrm{~s}$ at $12 \mathrm{~km}$ and at $18 \mathrm{~km}$ again indicate that the rainfall effect on $\overline{w^{\prime 2}}$ is much clearer in the afternoon than in the morning, and they are similar in magnitude between the OLR active and inactive phases. However, a slightly higher correlation is found in the OLR inactive phase than in the active phase.

Acknowledgments. The authors would like to express their gratitude to Profs. T. Tsuda, Kyoto University, and Y. N. Takayabu, the University of Tokyo, for their constructive comments and encouragements. They also thank Profs. S. Fukao, Tokai University, M. Yamamoto and H. Hashiguchi, both at Kyoto University, and 
LAPAN, Indonesia, for their overall management of the CPEA project. The CPEA project was conducted under the Grant-in-Aid for Scientific Research on Priority Areas funded by MEXT, Japan. OLR anomaly data were provided from Dr. M. Wheeler, BMRC, Australia.

\section{References}

Alexander, M. J. and J. R. Holton, A Model study of zonal forcing in the equatorial stratosphere by convectively induced gravity waves, J. Atmos. Sci., 54, 408-419, 1997.

Alexander, M. J., J. R. Holton, and D. R. Durran, The gravity wave response above deep convection in a squall line simulation, J. Atmos. Sci., 52, 2212-2226, 1995.

Alexander, M. J., H. H. Bares, and L. Pfister, Tropical stratospheric gravity wave activity and relationship to clouds, J. Geophys. Res., 105, 22,29922,309, 2000

Alexander, M. J., P. T. May, and J. H. Beres, Gravity waves generated by convection in the Darwin area during the Darwin Area Wave Experiment, J. Geophys. Res., 109, doi:10.1029/2004JD004729, 2004.

Alexander, S. P., T. Tsuda, J. Furumoto, T. Shimomai, T. Kozu, and M. Kawashima, A statistical overview of convection during the first CPEA campaign, J. Meteor. Soc. Jpn., 84A, 57-93, 2006.

Alexander, S. P., T. Tsuda, Y. Shibagaki, and T. Kozu, Seasonal gravity wave activity observed with the Equatorial Atmosphere Radar and its relation to rainfall information from the Tropical Rainfall Measuring Mission, J. Geophys. Res., 113, D02104, doi:10.1029/2007JD008777, 2008.

BMRC, http://www.bom.gov.au/bmrc/clfor/cfstaff/matw/maproom/OLR_ modes/index.htm, 2008.

Dhaka, S. K., M. Takahashi, Y. Kawatani, S. Malik, Y. Shibagaki, and S. Fukao, Observations of deep convective updrafts in tropical convection and their role in the generation of gravity waves, J. Meteor. Soc. Jpn., 81, 1185-1199, 2003.

Dhaka, S. K., M. K. Yamamoto, Y. Shibagaki, H. Hashiguchi, M. Yamamoto, and S. Fukao, Convection-induced gravity waves observed by the Equatorial Atmosphere Radar $\left(0.20^{\circ} \mathrm{S}, 100.32^{\circ} \mathrm{E}\right)$ in Indonesia, Geophys. Res. Lett., 32, L14820, doi:10.1029/2005GL022907, 2005.

Doviak, R. J. and D. S. Zrnic, Doppler Radar and Weather Observations, 562 pp., Academic Press, 1993.

Dutta, G., B. Bapiraju, P. Balasubrahmanyam, and H. A. Basha, VHF radar observations of gravity waves at a low latitude, Ann. Geophys., 17, 1012-1019, 1999.

Dutta, G., T. Tsuda, P. V. Kumar, M. C. A. Kumar, S. P. Alexander, and T. Kozu, Seasonal variation of short-period $(<2 \mathrm{~h})$ gravity wave activity over Gadanki, India $\left(13.5^{\circ} \mathrm{N}, 79.2^{\circ} \mathrm{E}\right)$, J. Geophys. Res., 113, D14103, doi:10.1029/2007JD009178, 2008.

Fovell, R., D. Durran, and J. R. Holton, Numerical simulations of convectively generated stratospheric gravity waves, J. Atmos. Sci., 49, 14271442, 1992.

Fukao, S., Copupling Processes in the Equatorial Atmosphere (CPEA): A project overview, J. Meteor. Soc. Jpn., 84A, CPEA Special Issue, 1-18, 2006.
Fukao, S., H. Hashiguchi, M. Yamamoto, T. Tsuda, T. Nakamura, M. K. Yamamoto, T. Sato, M. Hagio, and Y. Yabugaki, The Equatorial Atmosphere Radar (EAR): System description and first results, Radio Sci., 38, 1053, doi:10.1029/2002RS002767, 2003.

Kawashima, M., Y. Fujiyoshi, M. Ohi, T. Honda, T. Kozu, T. Shimomai, and H. Hashiguchi, Overview of Doppler radar observations of precipitating cloud systems in Sumatera Island during the first CPEA campaign, J. Meteor. Soc. Jpn., 84A, CPEA Special Issue, 33-56, 2006.

Kodama, Y.-M., M. Tokuda, and F. Murata, Convective activity over the Indonesian Maritime Continent during CPEA-I as evaluated by lightning activity and Q1 and Q2 profiles, J. Meteor. Soc. Jpn., 84A, CPEA Special Issue, 133-149, 2006.

Kozu, T., T. Shimomai, Z. Akramin, Marzuki, Y. Shibagaki, and H. Hashiguchi, Intraseasonal variation of raindrop size distribution at Koto Tabang, West Sumatra, Indonesia, Geophys. Res. Lett., 32, L07803, doi:10.1029/2004GL022340, 2005.

Kozu, T., K. K. Reddy, S. Mori, M. Thurai, J. T. Ong, D. N. Rao, and T. Shimomai, Seasonal and diurnal variations of raindrop size distribution in Asian monsoon region, J. Meteor. Soc. Jpn., 84A, CPEA Special Issue, 195-209, 2006.

Madden, R. A. and P. R. Julian, Observations of the 40-50-day tropical oscillation-A review, Mon. Wea. Rev., 122, 814-837, 1994.

Mori, S., J.-I. Hamada, Y. I. Tauhid, M. D. Yamanaka, N. Okamoto, F. Murata, N. Sakurai, H. Hashiguchi, and T. Sribimawati, Diurnal landsea rainfall peak migration over Sumatera Island, Indonesian maritime continent observed by TRMM satellite and intensive rawinsonde soundings, Mon. Wea. Rev., 132, 2021-2039, 2004.

Morita, J., Y. N. Takayabu, S. Shige, and Y. Kodama, Analysis of rainfall characteristics of the Madden-Julian oscillation using TRMM satellite data, Dyn. Atmosph. Ocea., 42, 107-126, 2006.

Shibagaki, Y., T. Shimomai, T. Kozu, S. Mori, Y. Fujiyoshi, H. Hashiguchi, M. K. Yamamoto, S. Fukao, and M. D. Yamanaka, Multi-scale aspects of convective systems associated with an intraseasonal oscillation over the Indonesian Maritime Continent, Mon. Wea. Review, 134, 16821696, 2006.

Tsuda, T., Y. Murayama, H. Wiryosumarto, S. B. Harijono, and S. Kato, Radiosonde observations of equatorial atmosphere dynamics over Indonesia, 2, characteristics of gravity waves, J. Geophys. Res., 99, 10,507-10,516, 1994

Wheeler, M. and G. N. Kiladis, Convectively coupled equatorial waves: Analysis of clouds and temperature in the wavenumber-frequency domain, J. Atmos. Sci., 56, 374-399, 1999.

Yamamoto, M. K., N. Nishi, T. Horinouchi, M. Niwano, and S. Fukao, Vertical wind observation in the tropical upper troposphere by VHF wind profiler: A case study, Radio Sci., 42, doi:10.1029/2006RS003538, 2007.

T. Kozu (e-mail: kozu@ecs.shimane-u.ac.jp), Y.-M. Kodama, Y. Shibagaki, T. Shimomai, M. Kawashima, and S. P. Alexander 